\title{
Lactobacillus rhamnosus HDB1258 modulates gut microbiota-mediated immune response in mice with or without lipopolysaccharide-induced systemic inflammation
}

Sang-Kap Han ${ }^{1 \dagger}$, Yeon-Jeong Shin ${ }^{1+}$, Dong-Yeon Lee ${ }^{1}$, Kyung Min Kim², Seo-Jin Yang ${ }^{2}$, Du Seong Kim², Ji-Whi Choi ${ }^{2}$, Seunghun Lee ${ }^{2}$ and Dong-Hyun Kim"

\begin{abstract}
Background: Gut microbiota closely communicate in the immune system to maintain a balanced immune homeostasis in the gastrointestinal tract of the host. Oral administration of probiotics modulates gut microbiota composition. In the present study, we isolated Lactobacillus rhamnosus HDB1258, which induced tumor necrosis factor (TNF)- $a$ and interleukin (IL)-10 expression in macrophages, from the feces of breastfeeding infants and examined how HDB1258 could regulate the homeostatic immune response in mice with or without lipopolysaccharide (LPS)-induced systemic inflammation.
\end{abstract}

Results: Oral administration of HDB1258 significantly increased splenic NK cell cytotoxicity, peritoneal macrophage phagocytosis, splenic and colonic TNF-a expression, TNF-a to IL-10 expression ratio, and fecal IgA level in control mice, while Th1 and Treg cell differentiation was not affected in the spleen. However, HDB1258 treatment significantly suppressed peritoneal macrophage phagocytosis and blood prostaglandin E2 level in mice with LPSinduced systemic inflammation. Its treatment increased LPS-suppressed ratios of Treg to Th1 cell population, Foxp3 to T-bet expression, and IL-10 to TNF-a expression. Oral administration of HDB1258 significantly decreased LPSinduced colon shortening, myeloperoxidase activity and $\mathrm{NF}-\mathrm{KB}^{+} / \mathrm{CD} 11 \mathrm{c}^{+}$cell population in the colon, while the ratio of IL-10 to TNF-a expression increased. Moreover, HDB1258 treatment shifted gut microbiota composition in mice with and without LPS-induced systemic inflammation: it increased the Cyanobacteria and PAC000664_9 (belonging to Bacteroidetes) populations and reduced Deferribacteres and EU622763_s group (belonging to Bacteroidetes) populations. In particular, PAC001066_g and PAC001072_s populations were negatively correlated with the ratio of IL-10 to TNF-a expression in the colon, while the PAC001070_s group population was positively correlated.

(Continued on next page)

\footnotetext{
* Correspondence: dhkim@khu.ac.kr

†Sang-Kap Han and Yeon-Jeong Shin contributed equally to this work.

${ }^{1}$ Neurobiota Research Center, College of Pharmacy, Kyung Hee University, 26, Kyungheedae-ro, Dongdaemun-gu, Seoul 02447, South Korea

Full list of author information is available at the end of the article
} 
(Continued from previous page)

Conclusions: Oral administered HDB1258 may enhance the immune response by activating innate immunity including to macrophage phagocytosis and NK cell cytotoxicity in the healthy host and suppress systemic inflammation in the host with inflammation by the modulation of gut microbiota and IL-10 to TNF-a expression ratio in immune cells.

Keywords: Lactobacillus rhamnosus HDB1258, Immunomodulation, Immune enhancement, Inflammation, Gut microbiota

\section{Background}

Gut microbiota closely communicate in the immune system to maintain a balanced immune homeostasis in the gastrointestinal tract of the host $[1,2]$. The alteration of gut microbiota by exposure to gastrointestinal environmental factors such as stress, pathogens, and probiotics cause the immune system of the gastrointestinal tract to fluctuate [3]. This exposure stimulates the secretion of proinflammatory and anti-inflammatory cytokines such as tumor necrosis factor (TNF)- $\alpha$ and interleukin (IL)-10 in the immune cells, $>70 \%$ of which are located in the gut $[4,5]$. These secreted cytokines regulate the immune system consisting of innate and adaptive immune systems. The activation of innate immune cells, which consist of phagocytic leukocytes and natural killer (NK) cells, by microbes stimulates the adaptive immune cells, which consist of $\mathrm{T}$ and $\mathrm{B}$ cells, through the regulation of cytokine expression $[5,6]$. The secretion of cytokines such as TNF- $\alpha$ and IL-10 in innate immune cells by the stimulation of pathogens promotes the differentiation of naïve $\mathrm{T}$ cells into effector $\mathrm{T}$ cells such as helper $\mathrm{T}$ (Th) and regulatory $\mathrm{T}$ (Treg) cells $[7,8]$. A wide imbalance between innate and adaptive immune systems, such as hyperimmunopotentiation and immunosuppression, is a high-risk factor for the outbreak of infectious diseases, chronic inflammation, autoimmunity, and cancers [9, 10]. Therefore, regulating the immune response in the gut may be beneficial for the therapy of peripheral and systemic immune disorders.

Probiotics including Lactobacilli, which are commonly found in fermented foods such as yogurt and kimchi and the gut microbiota of humans and animals, exhibit the beneficial physiological activities including the protection from pathogen infection and modulation of the immune system via the gastrointestinal tract [1113]. Lactobacillus reuteri alleviates ampicillin- or lipopolysaccharide-induced colitis and gut dysbiosis [14, 15]. TNF- $\alpha$ expression-inhibiting Lactobacillus johnsonii significantly alleviates 2,4,6-trinitrobenzenesulfonic acidor immobilization stress-generated gut inflammation and disruption in mice $[15,16]$. IL-6 expressioninhibitory Lactobacillus reuteri NK33 alleviates immobilization stress-generated gut inflammation and dysbiosis in mice [17]. TNF- $\alpha$ expression-inhibitory
Lactobacillus mucosae NK41 alleviates Escherichia coligenerated gut inflammation and dysbiosis in mice [18]. IL-10 expression-inducing Lactobacilli alleviate high-fat diet-generated gut inflammation and microbiota alteration in mice [19]. However, TNF- $\alpha$ express-inducing probiotics potentiate the immune response in mice [20]. These results suggest that probiotics are able to mitigate hyperresponsive and hyporesponsive immune responses. However, how probiotics can homeostatically regulate the immune responses remains unclear.

Therefore, we selected a probiotic Lactobacillus rhamnosus HDB1258 from bacterial strains isolated from the feces of breastfeeding infants and examined its effects on the innate and adaptive immune responses in the spleen and colon of mice with or without LPS-induced systemic inflammation.

\section{Results}

Effect of HDB1258 on the expression of TNF- $a$ and IL-10 in vitro

To understand whether probiotics could homeostatically modulate immune response (immunopotentiation and immunosuppression), first we selected three probiotics, which induced the expression of TNF- $\alpha$ in macrophages, from the collection of bacterial strains isolated from the feces of breastfeeding infants. Of these, HDB1258 most potently induced TNF- $\alpha$ and IL-10 expression in macrophage (Supplementary Fig. S1). HDB1258 also induced the expression of IL-6, a proinflammatory cytokine, and IL-10, an anti-inflammatory cytokine, in macrophage cells (Fig. 1). HDB1258 increased the expression ratio of TNF- $\alpha$ to IL-10. However, HDB1258 suppressed the expression of TNF- $\alpha$ and IL- 6 in LPS-stimulated macrophages and did not affect the expression of IL- 10 . Furthermore, it weakly increased the ratio of IL-10 to TNF- $\alpha$ expression in LPS-stimulated macrophages.

HDB1258 potentiated the immune response including the innate and adaptive immune systems in mice

First, to understand whether HDB1258 could activate the innate immune cells such as NK cells and macrophages, we orally gavaged HDB1258 or Saccharomyces cerevisiae (SC) $\beta$-glucan, which is known as an immunopotentiator [21], in mice and assayed the cytotoxicity of 


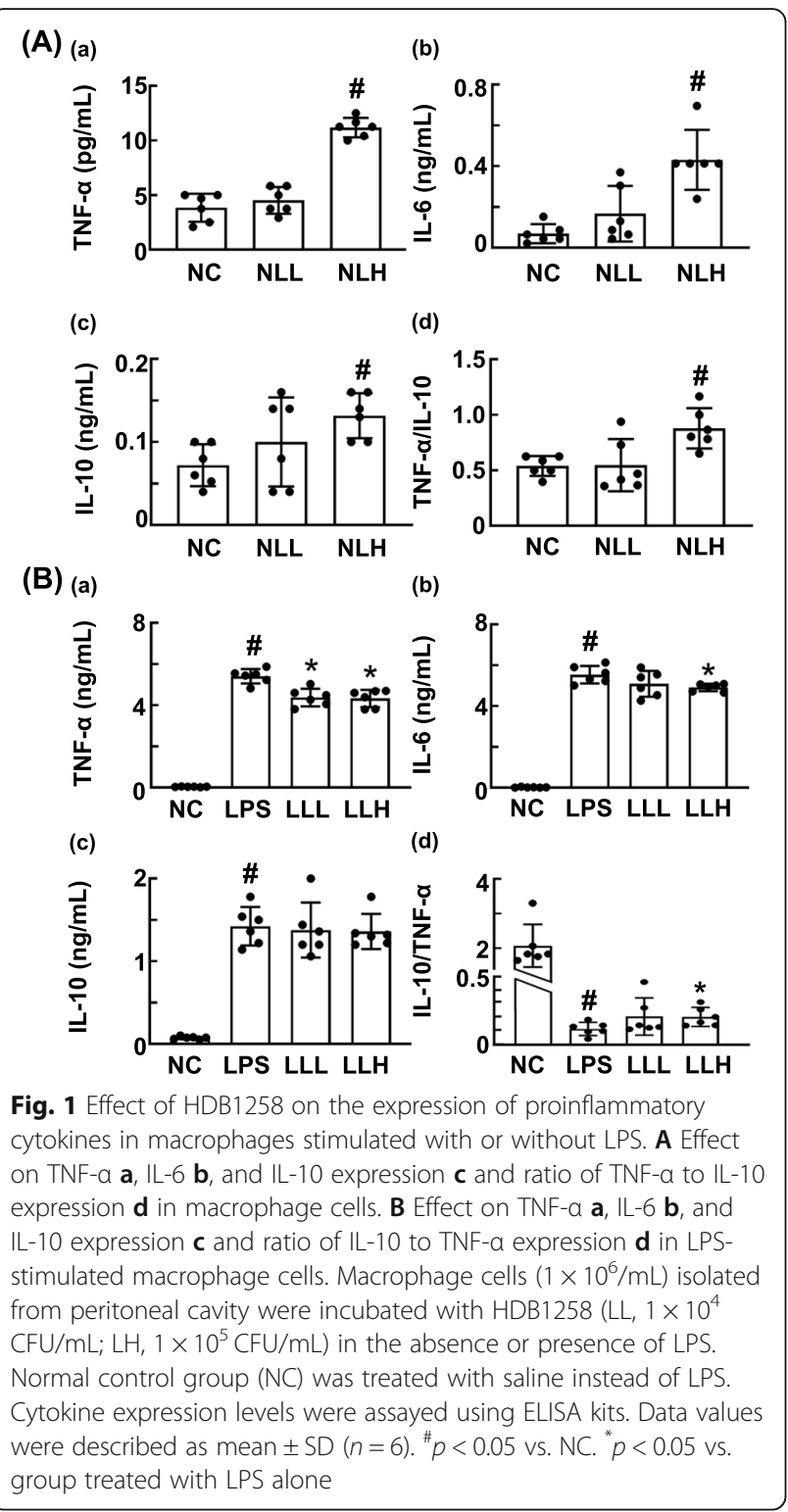

splenic NK cells against YAC-1 tumor cells and phagocytosis of peritoneal macrophages against Candida albicans (Fig. 2). Oral gavage of HDB1258 at a dose of $1 \times$ $10^{9} \mathrm{CFU} /$ mouse significantly increased splenic NK cell cytotoxicity and peritoneal macrophage phagocytic activity. Furthermore, oral HDB1258 increased the secretion of IgA into the feces. SC $\beta$-glucan at a dose of $50 \mathrm{mg} / \mathrm{kg}$ significantly increased the splenic NK cell activity, but not macrophage phagocytosis and IgA secretion.

Next, to understand whether HDB1258 could stimulate the adaptive immune cells such as $\mathrm{T}$ cells, we also examined the effect of HDB1258 on the $\mathrm{CD} 4^{+} \mathrm{IFN} \gamma^{+}$ (Th1) and $\mathrm{CD}_{4}{ }^{+} \mathrm{CD} 25^{+} \mathrm{Foxp}^{+}{ }^{+}$(Treg) cell differentiation and their transcription factor expression in the spleen of mice. Oral gavage of HDB1258 or SC $\beta$-glucan did not affect Th1 and Treg cell differentiation and their transcription factor expression. To confirm these immune responses, we assayed TNF- $\alpha$, a proinflammatory cytokine, and IL-10, an anti-inflammatory cytokine, in the spleen using qPCR. Treatment with HDB1258 or SC $\beta$-glucan increased significantly increased TNF- $\alpha$ expression. However, it did not significantly affect the expression of IL-10 in the spleen. As a result, oral gavage of HDB1258, but not SC $\beta$-glucan, increased the ratio of TNF- $\alpha$ to IL-10 expression in the spleen.

Oral gavage of HDB1258 at a dose of $1 \times 10^{9} \mathrm{CFU} /$ mouse or SC $\beta$-glucan at a dose of $50 \mathrm{mg} / \mathrm{kg}$ induced TNF- $\alpha$, IL-1 $\beta$, IL-6, and IL-10 expression in the in the colon (Fig. 3). In particular, it increased the ratio of TNF- $\alpha$ to IL-10 expression in the colon. They increased myeloperoxidase activity and $\mathrm{NF}-\mathrm{kB}^{+} / \mathrm{CD} 11 \mathrm{c}^{+}$cell population.

Effect of HDB1258 on gut microbiota composition in mice Gut microbiota are closely associated with gut immunity [1]. Probiotics significantly modulate the gut microbiota composition [12, 14]. Therefore, we examined whether the immunopotentiating effects of HDB1258 and SC $\beta$ glucan were associated with the composition of gut microbiota in mice (Fig. 4). Oral gavage of HDB1258 also modified the composition of gut microbiota in mice: it shifted $\beta$-diversity (principal coordinate analysis $[\mathrm{PCoA}]$ ) while the $\alpha$-diversity (operational taxonomic unit [OUT] richness) was not affected (Fig. 4a, b). HDB1258 treatment also increased the Cyanobacteria and Tenericutes populations and reduced the Firmicutes and Deferribacteres populations at the phylum level (Fig. 4c, Supplementary Tables S1, S2, S3). It also increased the Bacteroidaceae and FR888536_f (belonging to cyanobacteria) populations at the family level, PAC000664_g (belonging to Firmicutes), Paraprevotella, Muribaculaceae_uc populations at the genus level, and AB606242_s (belonging to Fimicutes), PAC001072_s (belonging to Bacteroidetes), and FJ880724_s (belonging to Bacteroidetes) population at the species level and reduced the Heliobacteriaceae, Deferribacteriaceae, and Coribacteriaceae populations at the family level, Prevotellaceae_uc, LLKB_g (belonging to Firmicutes), and Eubacterium_g6 populations at the genus level, and EU505186_s (belonging to Bacteroidetes) and AB626939_s (belonging to Firmicutes) populations at the species level. To determine whether gut microbiota are related to the immunopotentiating effects of HDB1258, we analyzed the correlation between the TNF- $\alpha$ to IL-10 expression ratio, which is the correlated with actual immune response in vivo [22, 23], and gut microbiota in mice treated with and without HDB1258 (Fig. 4d, Supplementary S2). Mycoplasmataceae $(\mathrm{R}=0.371, p=0.052)$, PAC001066_g $(\mathrm{R}=0.530, p=$ $0.069)$ PAC001765_g $(\mathrm{R}=0.585, p=0.002)$, Мyсоplasma_g10 $(\mathrm{R}=0.364, p=0.055)$, PAC001072_s $(\mathrm{R}=$ 
(A)

(a)

(b)

(c)
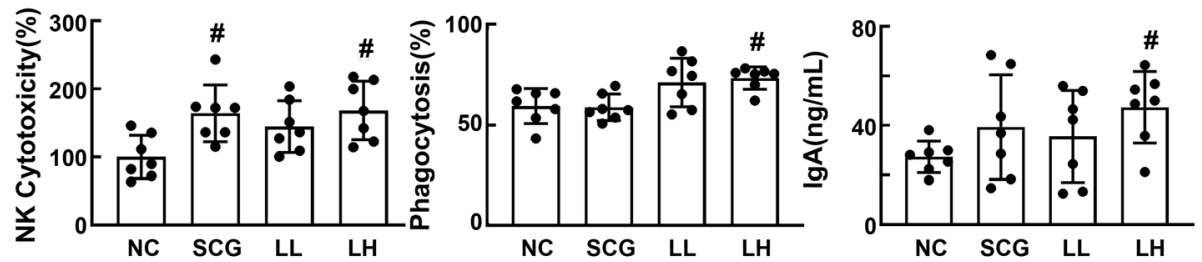

(B)

(a)

(b)

(c)
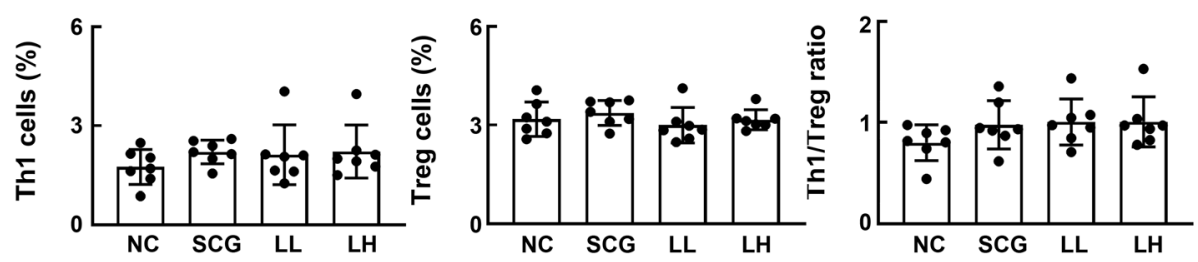

(C)

(a)

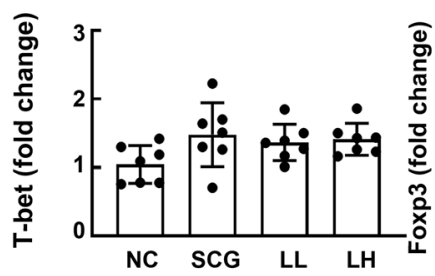

(D)

(a)

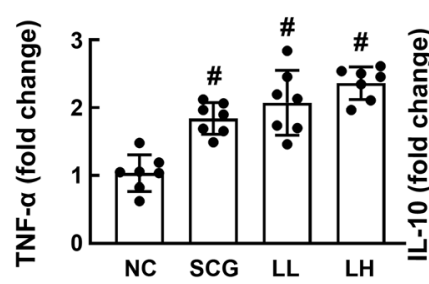

(b)

(c)

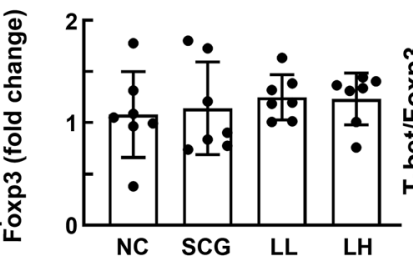

(b)

(c)

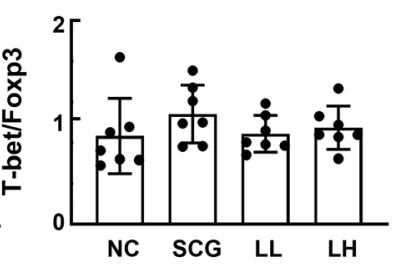

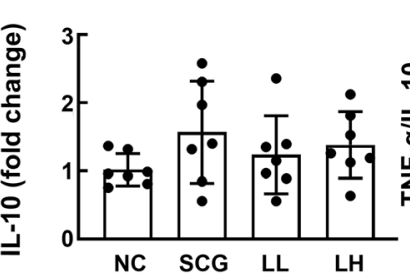

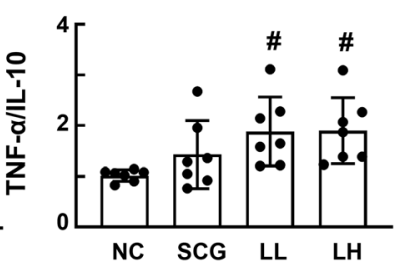

Fig. 2 Effect of HDB1258 and Saccharomyces cerevisiae (SC) B-glucan on splenic NK cell cytotoxicity, peritoneal macrophage phagocytosis, fecal lgA level, splenic Th1 and Treg cell differentiation, splenic T-bet, Foxp3, TNF-a, and IL-10 expression in mice. A Effects on splenic NK cell cytotoxicity a, peritoneal macrophage phagocytosis $\mathbf{b}$, and fecal IgA level $\mathbf{c}$. B Effects on the differentiation of Th1 $\mathbf{a}$ and Treg cells $\mathbf{b}$ and ratio of Th1 to Treg cells $\mathbf{c}$. $\mathbf{C}$ Effects on the expression of T cell transcription factors T-bet $\mathbf{a}$ and Foxp3 $\mathbf{b}$ and ratio of T-bet to Foxp3 expression $\mathbf{c}$. D Effects on the expression of TNF- $a \mathbf{a}$ and IL-10 b and ratio of TNF-a to IL-10 expression. HDB1258 (LL, $1 \times 10^{8}$ CFU/mouse/day and LH, $1 \times 10^{9}$ CFU/mouse/day) or SC $\beta$-glucan (SCG, 50 mg/kg/day) was orally gavaged daily for 14 days. Normal control mice (NC) were treated with vehicle (saline) instead of test agents. Cytokine expression levels were assayed using qPCR. Data values were described as mean \pm SD $(n=7) .{ }^{\#} p<0.05$ vs. NC

$0.055, p=0.002)$, PAC001076_s $(\mathrm{R}=0.604, p<0.001)$, PAC002476_s $(\mathrm{R}=0.382, p=0.045), \mathrm{PAC002451 \_ s}(\mathrm{R}=$ $0.654, \quad p<0.001), \quad$ PAC000198_g_uc $(\mathrm{R}=0.402, \quad p=$ $0.034)$, and PAC002480_s ( $R=0.500, p=0.007)$ populations showed a positive correlation with the ratio of TNF$\alpha$ to IL-10 expression in the colon. Frisingicoccus $(\mathrm{R}=$ - 0.472, $p=0.018)$, PAC002462_g $(\mathrm{R}=0 .-0.392, p=0.049)$, PAC001236_g $(\mathrm{R}=-0.360, p=0.051)$, PAC001070_s group
$(\mathrm{R}=-0.355, p=0.064)$ populations showed a negative correlation with the ratio of TNF- $\alpha$ to IL-10 expression in the colon. PAC001765_g $(\mathrm{R}=0.364, p=0.057)$, PAC001127_g $(\mathrm{R}=0.342, p=0.075)$, PAC001072_s $(\mathrm{R}=0.498, p=0.007)$, PAC001084_s $(\mathrm{R}=0.322, p=0.095)$, PAC001076_s $(\mathrm{R}=$ $0.385, p=0.043), \quad$ PAC002451_s $\quad(\mathrm{R}=0.454, p=0.015)$, PAC001081_s group $(\mathrm{R}=0.380, p=0.046)$, PAC001114_s $(\mathrm{R}=0.453, p=0.015)$, PAC001095_s $(\mathrm{R}=0.409, p=0.031)$, 
(a)

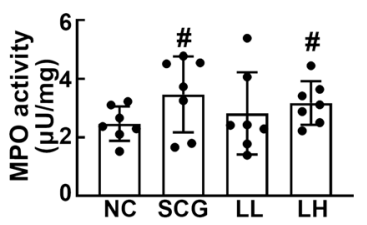

(d)

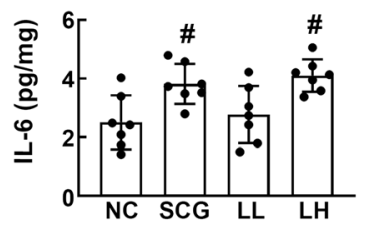

(b)

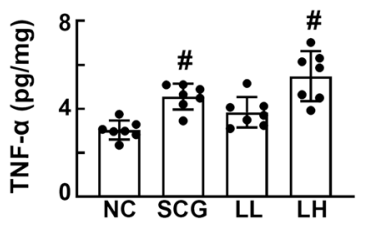

(e)

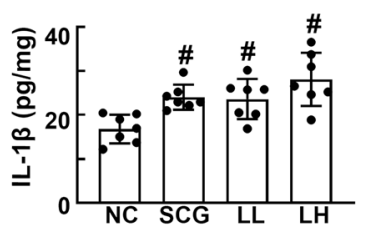

(c)

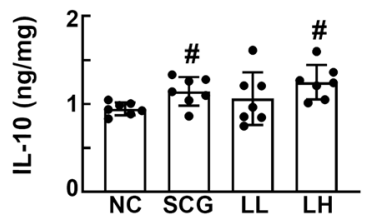

(f)

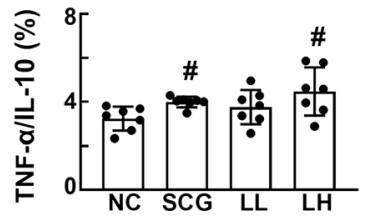

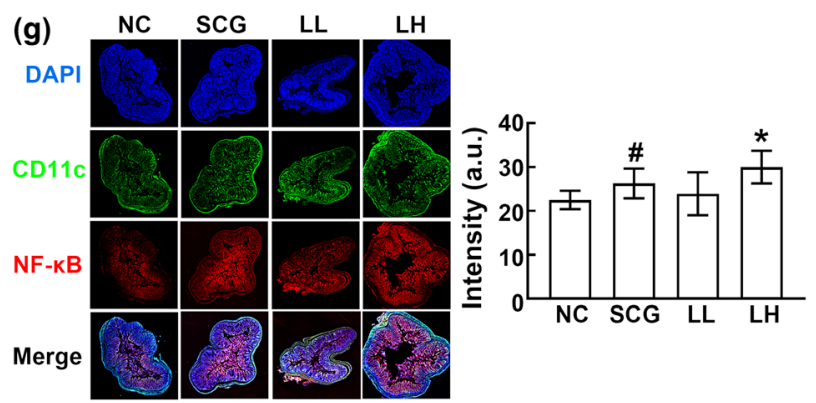

Fig. 3 Effect of HDB1258 and SC $\beta$-glucan on the myeloperoxidase activity $\mathbf{a}$, TNF- $a \mathbf{b}$, IL-10 c, IL-6 d, and IL-1 $\beta$ expression e, ratio of TNF-a to IL10 expression $\mathbf{f}$, and $\mathrm{NF}-\mathrm{KB}^{+} \mathrm{CD} 11 \mathrm{C}^{+}$cell population $\mathbf{g}$ in the colon of mice. HDB1258 (LL, $1 \times 10^{8} \mathrm{CFU} / \mathrm{mouse} /$ day and LH, $1 \times 10^{9} \mathrm{CFU} / \mathrm{mouse} /$ day) or SC $\beta$-glucan (SCG, $50 \mathrm{mg} / \mathrm{kg} /$ day) was orally gavaged daily for 14 days. Normal control mice (NC) were treated with vehicle (saline) instead of test agents. Cytokine expression levels were assayed using ELISA kits. Data values were described as mean \pm SD $(n=7) . " p<0.05$ vs. NC

PAC001113 s $(\mathrm{R}=0.448, p=0.017)$, and PAC002480 $\_\mathrm{s}$ $(\mathrm{R}=0.383, p=0.044)$ populations showed a positive correlation with the ratio of TNF- $\alpha$ to IL-10 expression in the spleen. Frisingicoccus $(\mathrm{R}=-0.368, p=0.054)$, PAC000197_ $\mathrm{g}(\mathrm{R}=-0.303, p=0.118)$, PAC001236_g $(\mathrm{R}=-0.327, p=$ $0.090)$ populations showed a negative correlation with the ratio of TNF- $\alpha$ to IL-10 expression in the spleen.

\section{HDB1258 alleviated LPS-induced inflammation in mice}

Next, we examined the effect of HDB1258 on the innate immune response including the cytotoxicity of NK cell and phagocytosis of macrophages in LPS-stimulated mice (Fig. 5a). Intraperitoneal injection of LPS significantly increased NK cell cytotoxicity against YAC-1 tumor cells and peritoneal macrophage phagocytic activity against Candida albicans. However, HDB1258 at a dose of $1 \times 10^{9} \mathrm{CFU} /$ mouse significantly suppressed macrophage phagocytosis, not LPS-induced NK cell cytotoxicity. Furthermore, HDB1258 treatment suppressed the LPS-induced PGE2 level. Next, we examined the effect of HDB1258 on LPS-induced systemic inflammation in mice (Fig. 5b). Intraperitoneal injection of LPS significantly decreased the $\mathrm{CD} 4{ }^{+} \mathrm{CD} 25^{+}$Foxp $3^{+}$(Treg) cell population in the spleen, while the $\mathrm{CD} 4^{+} \mathrm{IFN} \gamma^{+}$ (Th1) cell population was not affected. Nevertheless,
LPS treatment reduced the ratio of $\mathrm{CD} 4^{+} \mathrm{CD} 25^{+} \mathrm{Foxp} 3^{+}$ to $\mathrm{CD}_{4}^{+} \mathrm{IFN} \gamma^{+}$cell population. Oral gavage of HDB1258 did not significantly affect the population of Th1 or Treg cells. However, HDB1258 treatment recovered LPSsuppressed ratio of Treg to Th1 cell population. LPS treatment increased the expression of Th1 transcription factor T-bet in the spleen while the expression of Treg cell transcription factor Foxp3 was weakly, but not significantly, suppressed. Nevertheless, the ratio of Foxp3 to T-bet expression was increased by LPS treatment. However, oral gavage of HDB1258 significantly reduced LPS-induced T-bet expression, while the Foxp3 expression was not affected. Nevertheless, HDB1258 treatment recovered the LPS-suppressed ratio of Treg to Th1 cell population. LPS treatment increased the TNF- $\alpha$ expression, while IL-10 expression decreased. Moreover, its treatment decreased the ratio of IL-10 to TNF- $\alpha$ expression. Oral gavage of HDB1258 significantly suppressed LPS-induced TNF- $\alpha$ expression and induced LPSsuppressed IL-10 expression. Furthermore, HDB1258 treatment increased the LPS-suppressed ratio of IL-10 to TNF- $\alpha$ expression.

Furthermore, we examined the effect of HDB1258 on the colitis in mice with LPS-induced systemic inflammation (Fig. 6). Intraperitoneal injection of LPS induced 
(A)

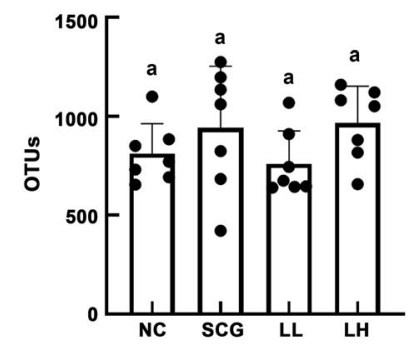

(B)

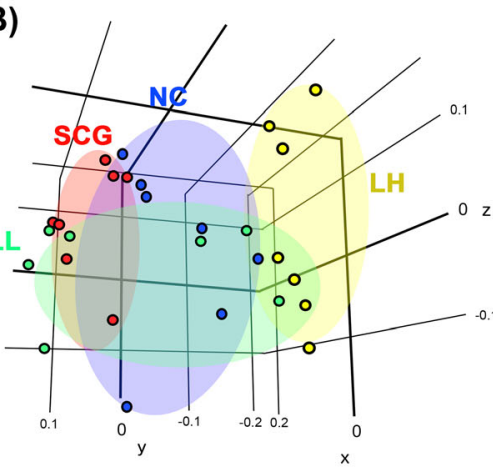

(b)

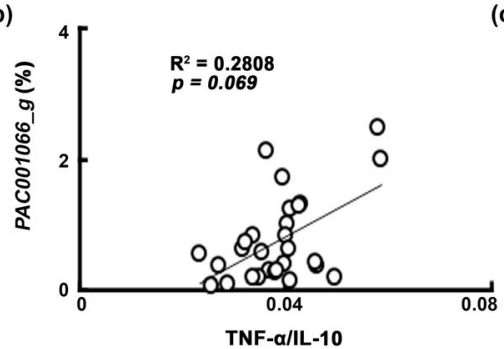

(C)

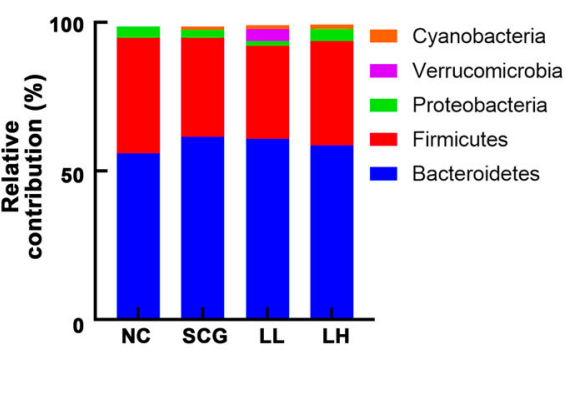

(c)

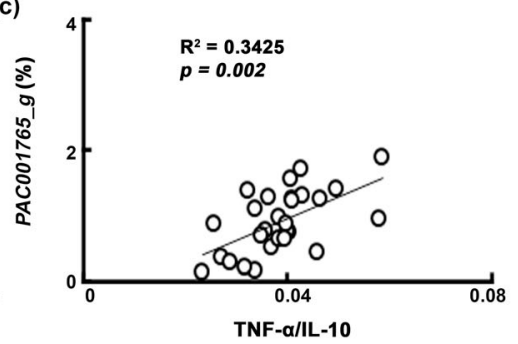

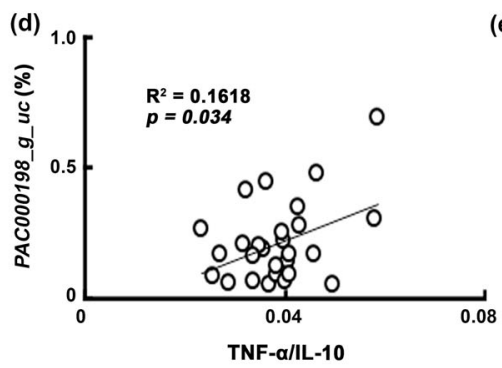

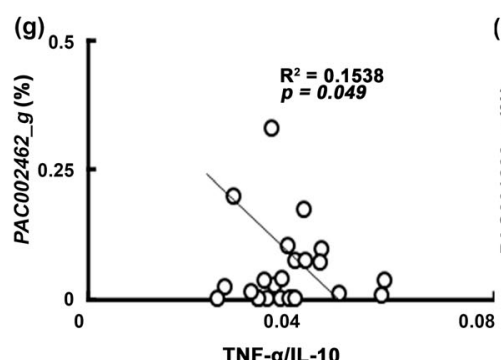

(e)

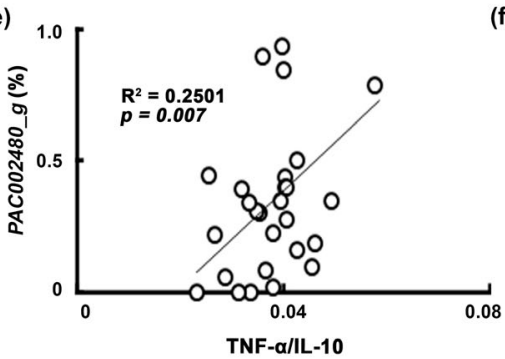

1

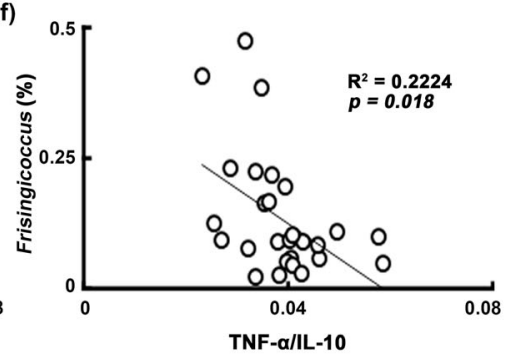

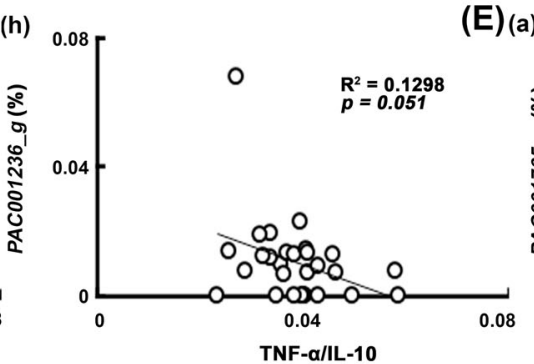
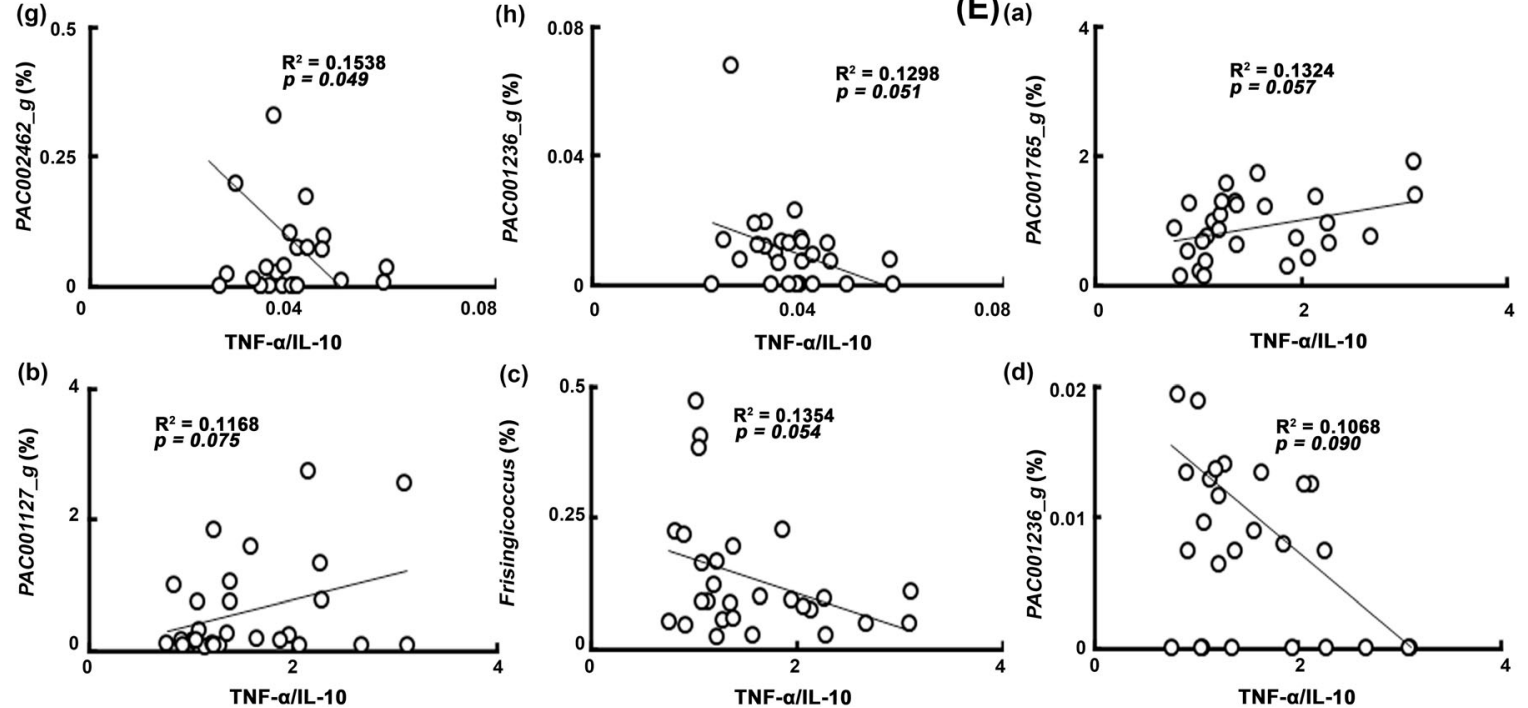

Fig. 4 Effect of HDB1258 and SC $\beta$-glucan on the gut microbiota composition in mice. A Effects on a-diversity (OUT richness). B Effects on $\beta$ diversity. C Effects on the gut bacteria composition at the phylum level. D The correlation between gut microbiota (at the family and genus levels) and ratio of TNF-a to IL-10 expression in the colon. $\mathbf{E}$ The correlation between gut microbiota (at the family and genus levels) and TNF- $\alpha$ to IL-10 expression ratio in the spleen. HDB1258 (LL, $1 \times 10^{8} \mathrm{CFU} /$ mouse/day and LH, $1 \times 10^{9} \mathrm{CFU} / \mathrm{mouse} /$ day) or SC $\beta-\mathrm{glucan}$ (SCG, $50 \mathrm{mg} / \mathrm{kg} / \mathrm{day}$ ) was orally gavaged daily for 14 days. Normal control group (NC) was treated with saline instead of test agents. Cytokine expression levels in the spleen were assayed using $\mathrm{qPCR}$ and those in the colon were using ELISA. Data values were described as mean \pm SD $(n=7) .{ }^{\#} p<0.05$ vs. NC 


\section{(A)}

(a)

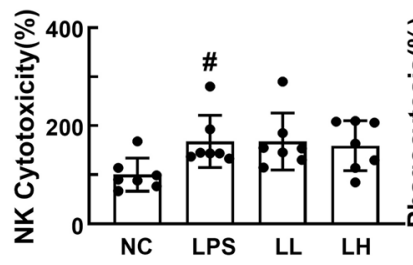

(B)

(a)

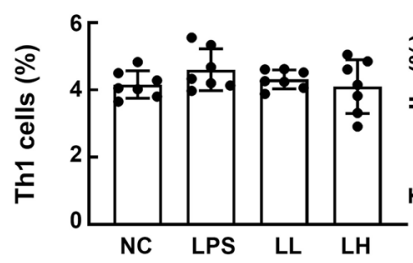

(b)

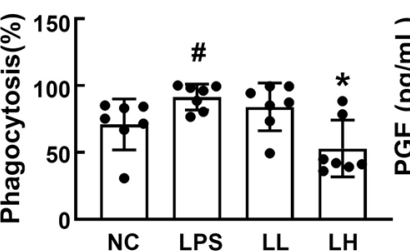

(c)

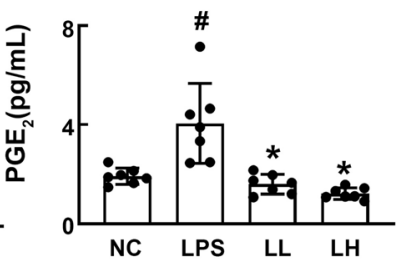

(c)
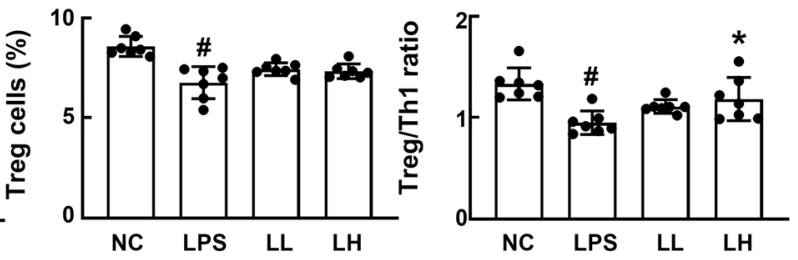

(C)

(a)

(b)

(c)
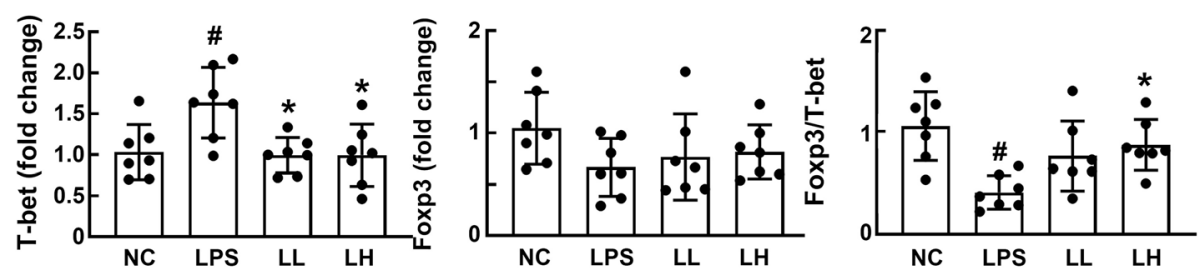

(D)

(a)

(b)

(c)
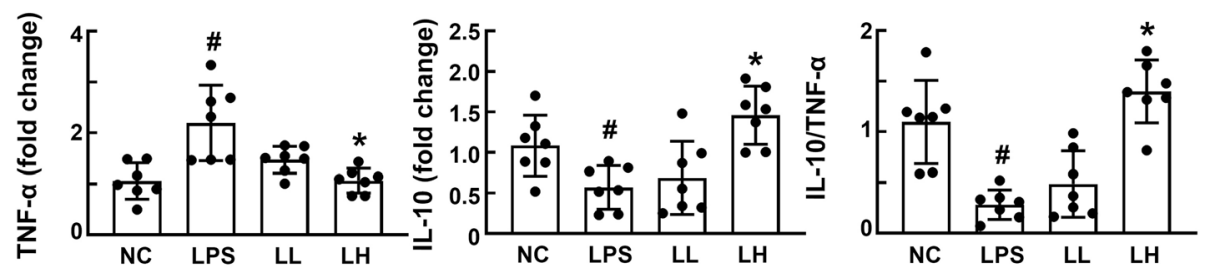

Fig. 5 Effect of HDB1258 on splenic NK cell cytotoxicity, peritoneal macrophage phagocytosis, blood PGE2 level, splenic Th1 and Treg cell differentiation, splenic T-bet, Foxp3, TNF-a, and IL-10 expression in mice with LPS-induced systemic inflammation. A Effects on splenic NK cell cytotoxicity $\mathbf{a}$, peritoneal macrophage phagocytosis $\mathbf{b}$, and blood PGE2 level $\mathbf{c}$. B Effects on the differentiation of Th1 $\mathbf{a}$ and Treg cells $\mathbf{b}$ and ratio of Th1 to Treg cells $\mathbf{c}$. C Effects on the expression of T cell transcription factors T-bet $\mathbf{a}$ and Foxp3 $\mathbf{b}$ and ratio of T-bet to Foxp3 expression $\mathbf{c}$. $\mathbf{D}$ Effects on the expression of TNF- $a \mathbf{a}$ and IL-10 $\mathbf{b}$ and ratio of TNF- $a$ to IL-10 expression C. Mice was interaperitoneally injected with LPS (10 $\mu \mathrm{g} /$ $\mathrm{kg} /$ day) for 10 days. HDB1258 (LPS, vehicle; LL, $1 \times 10^{8} \mathrm{CFU} / \mathrm{mouse} /$ day and $\mathrm{LH}, 1 \times 10^{9} \mathrm{CFU} / \mathrm{mouse} /$ day) was orally gavaged daily for 14 days from the final injection of LPS. Normal control mice (NC) were treated with saline instead of LPS and test agents. Cytokine expression levels were assayed using qPCR. Data values were described as mean $\pm \mathrm{SD}(n=7) .{ }^{\#} p<0.05$ vs. NC. ${ }^{*} p<0.05$ vs. group treated with LPS alone

colitis: it induced colon shortening, IL-1ß, IL-6, and TNF$\alpha$ expression and suppressed IL-10 expression in the colon. In particular, LPS treatment increased the TNF- $\alpha$ to IL-10 expression ratio and $\mathrm{NF}-\mathrm{kB}^{+} \mathrm{CD} 11 \mathrm{c}^{+}$cell population in the colon. However, oral gavage of HDB1258 significantly inhibited LPS-induced colon shortening and myeloperoxidase activity and $\mathrm{NF}-\mathrm{kB}^{+} / \mathrm{CD} 11 \mathrm{c}^{+}$cell population. Furthermore, its treatment increased the ratio of IL-10 to TNF- $\alpha$ expression in the colon.

HDB1258 partially modified LPS-disturbed gut microbiota composition in mice

Next, we examined whether the anti-inflammatory effects of HDB1258 were associated with the gut 


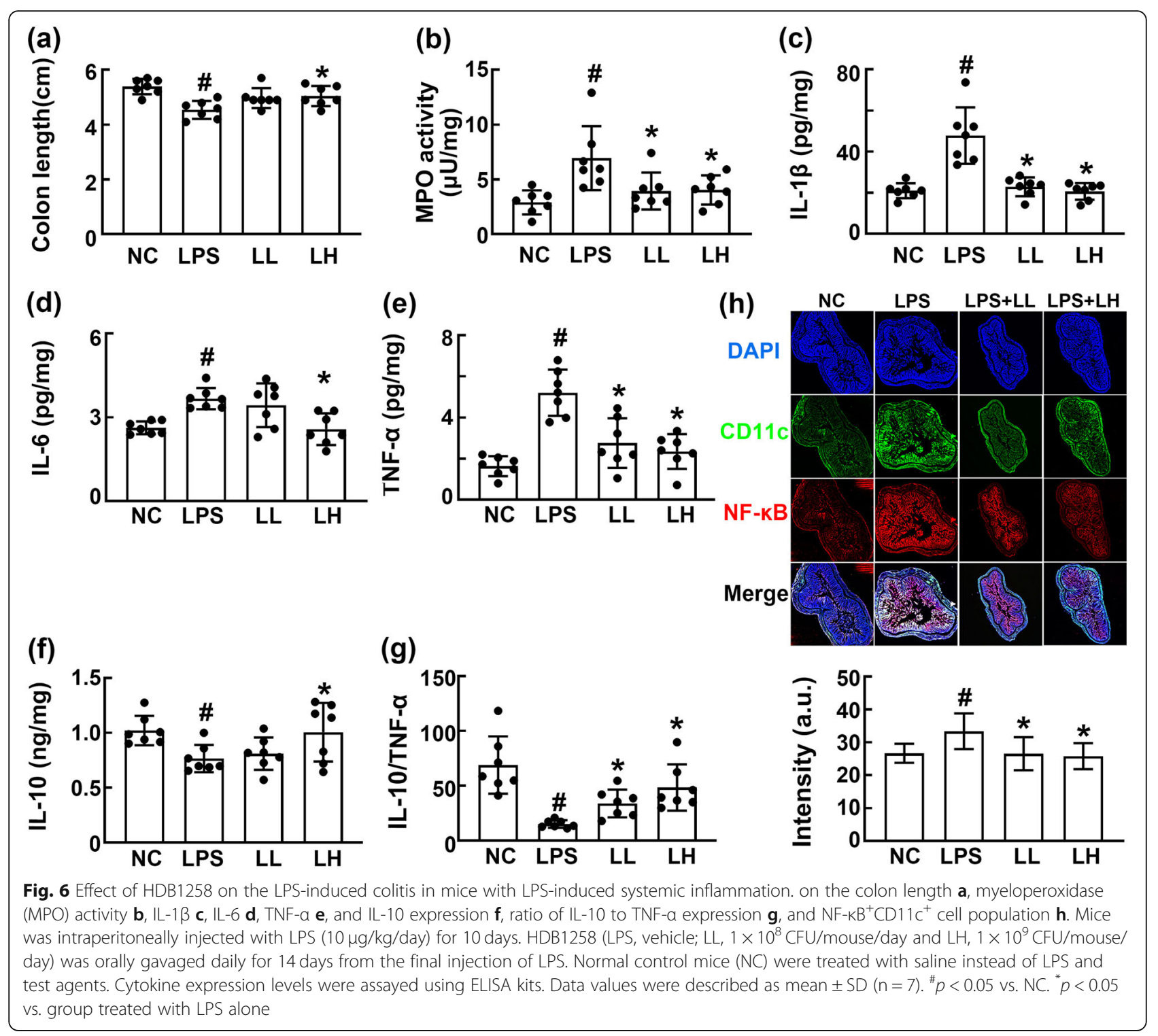

microbiota composition in mice (Fig. 7). Exposure to LPS also caused gut microbiota alteration in mice: it shifted $\beta$-diversity (PCoA) while the $\alpha$-diversity (OTU richness) was not affected (Fig. 7a, b). Furthermore, it increased cyanobacteria population and reduced the Tenericutes, Verrucomicrobia, and Deferribacteres populations (Fig. 7c, Supplementary Tables S4, S5, S6). Oral gavage of HDB1258 changed LPS-shifted $\beta$-diversity in the gut microbiota, while the $\alpha$-diversity was weakly, but not significantly, affected. HDB1258 treatment also increased LPS-suppressed Tenericutes, Verrucomicrobia, and Deferribacteres populations at the phylum level, Lachnospiraceae, Rikenellaceae, Helicobacteriaceae, Akkermansiaceae, Odoribacteriaceae, and Deferribacteraceae populations at the family level, KE159538_g (belonging to Firmicutes), PAC000664_g (belonging to Bacteroidetes), and Muribaculum populations at the genus level, and PAC001696_s (Firmicutes), PAC001120_s (belonging to Firmicutes), and PAC001077_s (belonging to Bacteroidetes) populations at the species level and reduced LPSinduced Erysipelotrichaceae population at the family level, Ruminococcus population at the genus level, and EU622763_s group (belonging to Bacteroidetes) population at the species level. To determine whether gut microbiota are related to the anti-inflammatory effect of HDB1258, we analyzed the correlation between the ratio of IL-10 to TNF- $\alpha$ expression and gut microbiota in mice with LPS-induced systemic inflammation (Fig. 7d, Supplementary Fig. S3). Rikenellaceae $(\mathrm{R}=0.507, p=0.059)$, Lactobacillus $(\mathrm{R}=0.462, \quad p=0.014), \quad$ Eubacterium_g23 $(\mathrm{R}=0.495, p=0.007)$, PAC001070_s group $(\mathrm{R}=0.418, p=$ 0.027), Lactobacillus murinus group $(\mathrm{R}=0.449, p=0.017)$, 
(A)

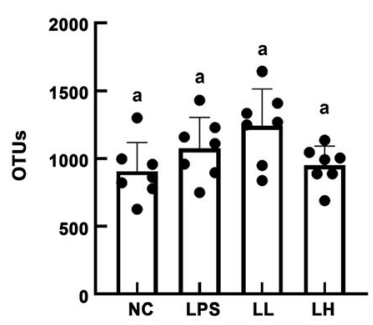

(B)

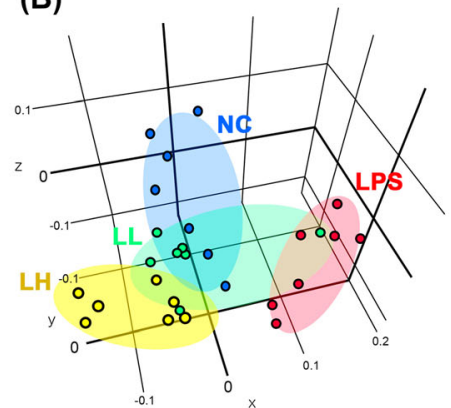

(C)

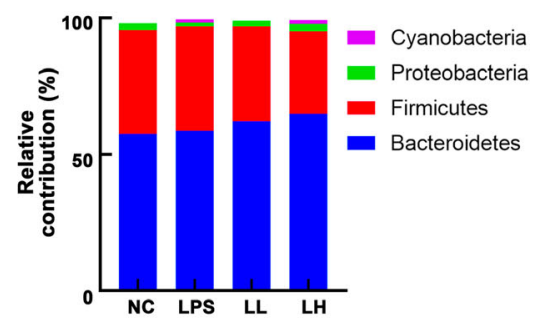

(D)(a)
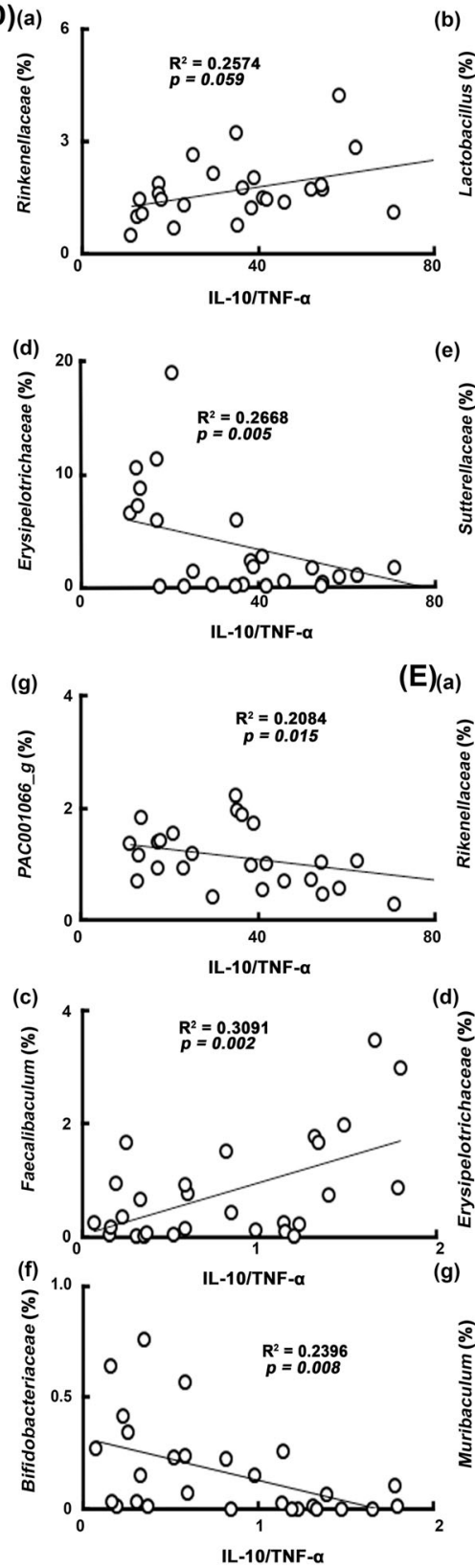
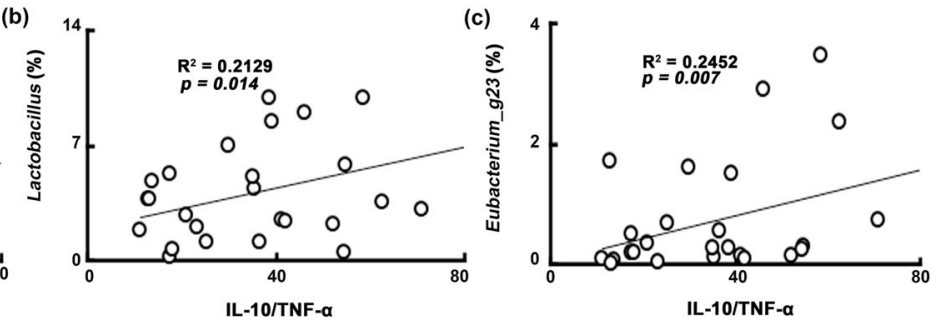

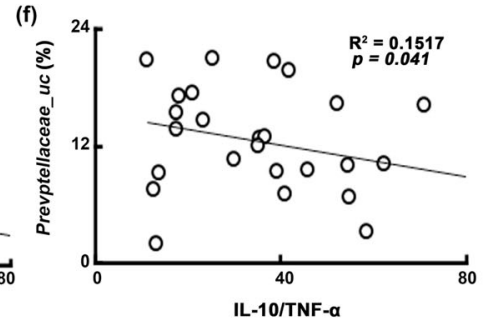

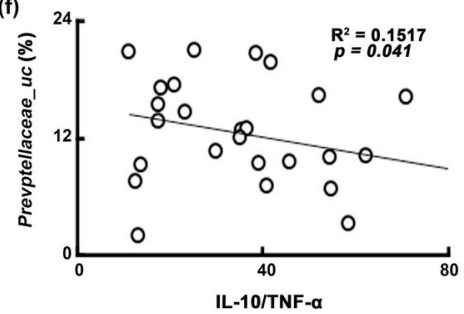

(b)

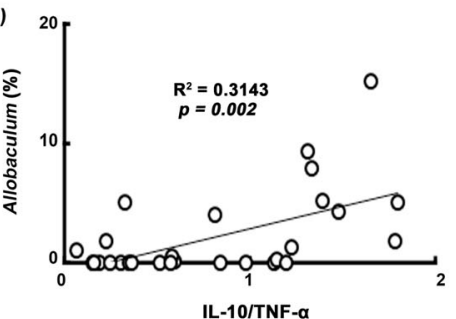

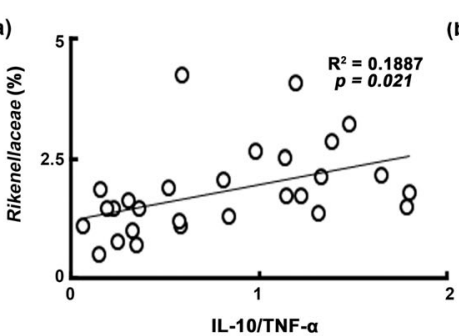

(e)
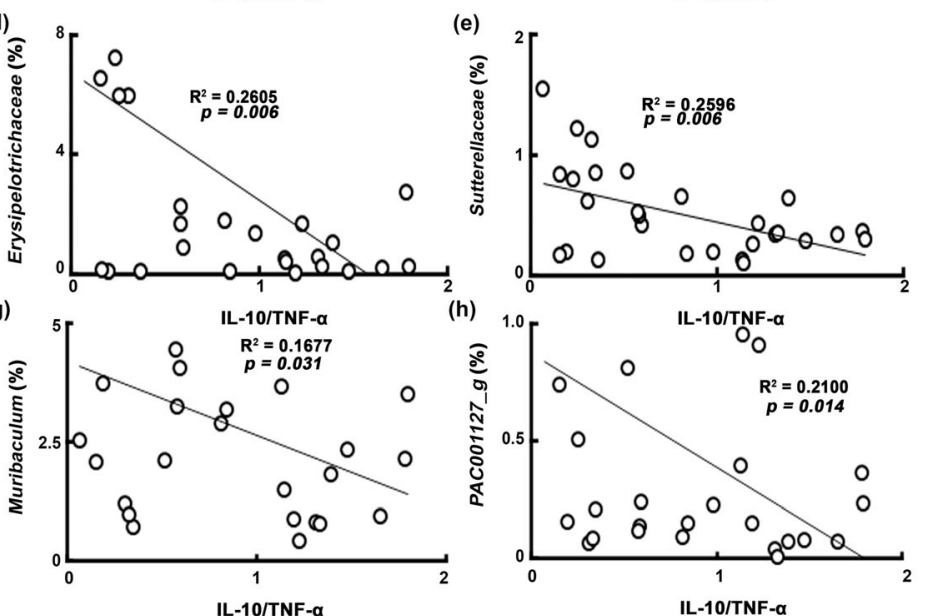

Fig. 7 (See legend on next page.) 
(See figure on previous page.)

Fig. 7 Effect of HDB1258 on the composition of gut microbiota in mice with LPS-induced systemic inflammation. A Effects on a-diversity (OUT richness). B Effects on $\beta$-diversity. C Effects on the gut bacteria composition at the phylum level. D The correlation between gut microbiota (at the family and genus levels) and ratio of IL-10 to TNF-a expression in the colon. $\mathbf{E}$ The correlation between gut microbiota (at the family and genus levels) and ratio of IL-10 to TNF-a expression in the spleen. Mice was intraperitoneally injected with LPS (10 $\mu \mathrm{g} / \mathrm{kg} / \mathrm{day})$ for 10 days. HDB1258 (LPS, vehicle; LL, $1 \times 10^{8} \mathrm{CFU} /$ mouse/day and LH, $1 \times 10^{9} \mathrm{CFU} /$ mouse/day) was orally gavaged daily for 14 days from the final injection of LPS. Normal control mice (NC) were treated with vehicle (saline) instead of LPS and test agents. Cytokine expression levels in the spleen were assayed using qPCR and those in the colon were using ELISA. Data values were described as mean \pm SD $(n=7) .{ }^{*} p<0.05$ vs. NC. ${ }^{*} p<0.05$ vs. group treated with LPS alone

Lactobacillus reuteri group $(\mathrm{R}=0.412, \quad p=0.029)$, PAC001982_s $(\mathrm{R}=0.434, p=0.021), \quad$ PAC000661_g_uc $(\mathrm{R}=0.632, p<0.001)$ populations showed a positive correlation with the ratio of IL-10 to TNF- $\alpha$ expression in the colon. Erysipelotrichaceae $(\mathrm{R}=-0.517, p=0.005)$, Sutterellaceae $(\mathrm{R}=-0.478, p=0.010)$, Prevotellaceae_uc $(\mathrm{R}=-$ 0.389, $p=0.041)$, PAC001066_g $(\mathrm{R}=-0.457, p=0.015)$, PAC001072_s $(\mathrm{R}=-0.362, p=0.059), \mathrm{PAC} 001066 \_\mathrm{s}(\mathrm{R}=$ $-0.475, p=0.011)$, PAC002478_s $(\mathrm{R}=-0.488, p=0.009)$, PAC001756_s $(\mathrm{R}=-0.614, p<0.001)$ populations showed a negative correlation with the ratio of IL-10 to TNF- $\alpha$ expression in the colon. Rikenellaceae $(\mathrm{R}=0.434, p=0.021)$, Odoribacteraceae $(\mathrm{R}=0.406, \quad p=0.032), \quad$ PAC000661_g $(\mathrm{R}=0.394, p=0.038)$, Allobaculum $(\mathrm{R}=0.561, p=0.002)$, Faecalibaculum $(\mathrm{R}=0.556, p=0.002)$, Bacteroides acidifaciens group $(\mathrm{R}=0.412, p=0.029)$, PAC001081_s group $(\mathrm{R}=0.420, p=0.026)$, and FJ880578_s $(\mathrm{R}=0.537, p=$ $0.003)$ populations showed a positive correlation with the ratio of IL-10 to TNF- $\alpha$ expression in the spleen. Erysipelotrichaceae $(\mathrm{R}=-0.510, p=0.006)$, Sutterellaceae $(\mathrm{R}=-0.510, p=0.006)$, Bifidobacteriaceae $(\mathrm{R}=-0.489$, $p=0.008), \quad$ Muribaculum $\quad(\mathrm{R}=-0.410, \quad p=0.031)$, PAC001127_g $\quad(\mathrm{R}=0.458, \quad p=0.014), \quad$ PAC001084_S $(\mathrm{R}=-0.388, p=0.042)$, and PAC001756_s $(\mathrm{R}=-0.531$, $p=0.004)$ populations showed a negative correlation with the ratio of IL-10 to TNF- $\alpha$ expression in the spleen.

\section{Discussion}

The immune system consists of innate and adaptive immune systems that cooperatively protect the body from pathogenic microbes and toxins [10, 24]. The attack of pathogenic microbes and toxins activates innate immune cells such as macrophages, dendritic cells, and NK cells, which secrete interferon (IFN)- $\gamma$, TNF- $\alpha$, IL-1 $\beta$, IL-6, and IL-10 [4, 25]. These cytokines stimulate adaptive immune cells such as $\mathrm{T}$ cells, resulting in the differentiation of naïve $\mathrm{T}$ cells into Th1, Th2, Th17, and Treg cells $[4,25,26]$. The immunosuppression of host immune systems by stressors such as anticancer therapy cannot defend against pathogens and tumor progression. The hyperimmune responsiveness of host immune systems by pathogens, toxins, and allergens such as LPS excessively causes hypersensitivity including chronic inflammation through the activation of antigen-presenting cells and Th1/Treg cells $[8,26]$. A wide imbalance in innate and adaptive immune systems perturbs gut microbiota, which can affect host systemic immune system through the regulation of the gut immune system $[1,3$, 27]. Therefore, maintaining a delicate balance in the immune system by protecting against infection by pathogens and toxins is important for the body's health.

In the present study, we found that oral administration of HDB1258, a novel probiotic isolated from healthy infant feces, significantly induced splenic NK cell cytotoxicity against YAC-1 tumor cells, peritoneal macrophage phagocytosis against Candida albicans, TNF- $\alpha$ to IL-10 expression ratio in the spleen, and TNF- $\alpha$, IL- $1 \beta$, and IL-6 expression in the colon,. Furthermore, HDB1258 increased the secretion of IgA into the feces, which serves as the first line of defense in protecting the gastrointestinal tract from pathogens and their toxins $[28,29]$. However, it did not affect the differentiation of Th1 and Treg cells and expression of their transcription factors T-bet and Foxp3 in the systemic immune cellrepresentable spleen. These results suggest that HDB1258 may enhance the immune response by activating innate immunity including macrophage phagocytosis and NK cell cytotoxicity, not adaptive immunity, in a healthy host.

The intraperitoneal injection of LPS caused systemic inflammation: it induced the phagocytosis of peritoneal macrophages against Candida albicans, while the ratios of Treg to Th1 cell differentiation and Foxp3 to T-bet expression and IL-10 to TNF- $\alpha$ expression in the spleen and colon were suppressed. However, oral administration of HDB1258 increased the differentiation of Treg cells, not Th1 cells, while macrophage phagocytosis decreased. Furthermore, HDB1258 treatment significantly suppressed T-bet and TNF- $\alpha$ expression and induced the expression of IL-10 in the spleen, resulting in an increase in the ratios of Foxp3 to T-bet and IL-10 to TNF$\alpha$ expression. Oral administration of HD1258 also suppressed LPS-induced colon shortening, myeloperoxidase activity, TNF- $\alpha$, IL- $1 \beta$, and IL- 6 expression in the colon, while IL-10 expression increased. Furthermore, it increased the LPS-suppressed ratio of IL-10 to TNF- $\alpha$ expression. Villena et al. reported that Lactobacillus rhamnosus suppressed the immune response by 
regulating the expression of IL-10, an anti-inflammatory cytokine [30]. Nigar et al. reported that Lactobacillus rhamnosus potentiated the immune response by inducing the expression of IL-6 [31]. These results suggest that HDB1258 can suppress systemic inflammation including colitis by increasing the expression ratio of antiinflammatory cytokines such as IL-10 to proinflammatory cytokines such as TNF- $\alpha$.

In addition, Zhang et al. reported that Lactobacillus rhamnosus GG suppressed allergic airway inflammation in mice by inducing the Treg cell population, which was closely associated with gut microbiota composition [32]. Wang et al. reported that Lactobacillus rhamnosus GG enhanced TNF- $\alpha$, IL-6, and IL-10 expression in gnotobiotic pigs vaccinated with an oral attenuated human rotavirus vaccine [33]. They suggested that Lactobacillus rhamnosus GG may regulate the homeostatic immune response by the modulation of gut microbiota. In the present study, we found that Lactobacillus rhamnosus enhanced the immune response in the healthy host by activating innate immune cells and suppressed the inflammatory response in the host with LPS-induced systemic inflammation by regulating innate and adaptive immune cells through the ratio of IL-10 to TNF- $\alpha$ expression. Moreover, oral administration of HDB1258 modified gut microbiota in mice with and without systemic inflammation. HDB1258 treatment also increased the Cyanobacteria and PAC000664_g (belonging to Bacteroidetes) populations and reduced Deferribacteres and EU622763_s group (belonging to Bacteroidetes) populations in mice with or without LPS-induced systemic inflammation. In particular, PAC001066_g and PAC001072_s populations showed a negative correlation with the ratio of IL-10 to TNF- $\alpha$ expression in the colon. PAC001070_s group population showed a positive correlation with the ratio of IL-10 to TNF- $\alpha$ expression in the colon of mice with or without LPS-induced systemic inflammation. PAC001127_g, and PAC001084_s, and PAC001756_s populations showed a negative correlation with the ratio of IL-10 to TNF- $\alpha$ expression in the spleen of mice with or without LPS-induced systemic inflammation. These cytokines are expressed in the gut immune cells such as macrophages, dendritic cells, and NK cells by the infection of pathogens into the gastrointestinal tract, resulting in the exclusion of pathogens in the host $[4,25]$. However, if not excluded, chronic inflammation can be caused [25, 34]. Therefore, these immune-imbalanced diseases may be due to the hypoexpression of anti-inflammatory cytokines such as IL-10 or overexpression of proinflammatory cytokines such as TNF- $\alpha$. Moreover, gut dysbiosis causes immune diseases including gastrointestinal inflammation $[3,35]$. These results suggest that gut microbiota composition is closely associated with gut immune responses including the ratio of IL-10 to TNF- $\alpha$ expression and HDB1258 can regulate the immune responses by modulating the microbiota composition.

\section{Conclusions}

HDB1258 may enhance the immune response by activating innate immunity including to macrophage phagocytosis and NK cell cytotoxicity, not the adaptive immunity, in the healthy host. HDB1258 can suppress systemic inflammation by increasing the expression ratio of anti-inflammatory cytokines such as IL-10 to proinflammatory cytokines such as TNF- $\alpha$. HDB1258 may regulate the immune system including gut immune response by modulating the microbiota composition. Finally, HDB1258 may enforce the maintenance of a balanced immune response by the modulation of gut microbiota and IL-10 to TNF- $\alpha$ expression ratio in the immune cells.

\section{Materials and methods Materials}

Sodium thioglycolate, 4',6-diamidino-2-phenylindole, dilactate (DAPI), and RPMI 1640 were purchased from Sigma (St. Louis, MO). Enzyme-linked immunosorbent assay (ELISA) kits for IL-1 $\beta$, IL-6, IL-10, and TNF- $\alpha$ were purchased from eBioscience (San Diego, CA). Antibodies were purchased from Cell Signaling Technology (Beverly, MA). CD4 T and NK cell isolation kits were purchased from Miltenyi Biotec (Teterow, Germany). A Vybrant CFDA SE Cell Tracer kit was purchased from Invitrogen (Grand Island, NY). A QIAamp DNA stool mini kit was purchased from Qiagen (Hiden, Germany).

\section{Culture of Lactobacillus rhamnosus HDB1258}

HDB1258, isolated from breastfeeding infants (data not shown), was identified as Lactobacillus rhamnosus on the basis on the results of Gram staining, 16S rDNA sequencing (GenBank accession number MW193326), and API 50 CHL kit. Lactobacillus rhamnosus HDB1258 (HDB Cell Bank, Hyundae Bioland Co., Ltd., Korea) was inoculated into lava-seawater LAB media containing $8 \%$ glucose, $2 \%$ yeast extract, $0.5 \%$ soy peptone, $0.5 \%$ sodium acetate, $0.1 \%$ Tween $80,0.01 \% \mathrm{MgSO}_{4}, 0.005 \% \mathrm{MnSO}_{4}$, $0.2 \%$ potassium diphosphate, and $0.2 \%$ ammonium sulfate in $30 \%(\mathrm{v} / \mathrm{v})$ lava-seawater $(\mathrm{pH} 6.5)$, incubated at $37^{\circ} \mathrm{Cfor} 20 \mathrm{~h}$, and centrifuged $(5000 \mathrm{~g}, 30 \mathrm{~min})$ [36]. The resulting precipitate was mixed with hydroxypropyl methylcellulose and trehalose and freeze-dried. For the in vitro and in vivo experiments, it was suspended in saline and the number of viable HDB1258 was counted before used in experiment. 


\section{Animals}

C57BL/6 mice (male, 5 weeks old, $19 \sim 21 \mathrm{~g}$ ) were supplied from Orient Bio (Seongnam-shi, Korea) and acclimatized for 7 days before the usage of experiments. All animals were maintained in the plastic cage with the 5 cm-raised wire floor under standard conditions (temperature, $20 \pm 2{ }^{\circ} \mathrm{C}$; humidity, $50 \pm 10 \%$, and lighting, $12 \mathrm{~h}$ /day). All mice were fed standard laboratory chow and tap water ad libitum. Animal experiments were conducted according to the NIH, University Guide for Laboratory Animal Care and Usage, and ARRIVE guidelines (https://arriveguidelines.org).

\section{Isolation and culture of macrophages}

Macrophages, which were isolated from the peritoneal cavity of mice intraperitoneally injected with sodium thioglycolate according to the method of Jang et al. [17], were suspended in RPMI 1640 containing 10\% fetal bovine serum and $1 \%$ antibiotics (RFA), seeded in 6-well plate, incubated at $37^{\circ} \mathrm{C}$ for a day, and washed with
RFA, as previously reported [14]. For the assay of IL-10 and TNF- $\alpha$ expression, macrophages were treated with LPS $(80 \mathrm{ng} / \mathrm{mL})$ in the presence or absence of HDB1258 (LL, $1 \times 10^{4} \mathrm{CFU} / \mathrm{mL}$; LH, $\left.1 \times 10^{5} \mathrm{CFU} / \mathrm{mL}\right)$ ) for $20 \mathrm{~h}$ [17].

\section{Treatment with HDB1258, a probiotic, in mice with or} without LPS-induced systemic inflammation

To examine the immunomodulating effect of HDB1258, it was orally gavaged in mice with or without LPSinduced systemic inflammation. Normal control mice were orally gavaged with vehicle (saline) instead of HDB1258 (Fig. 8). Each group consisted of 7 mice. First, HDB1258 (LL, $1 \times 10^{8} \mathrm{CFU} /$ mouse/day; LH, $1 \times 10^{9}$ $\mathrm{CFU} / \mathrm{mouse} /$ day) or SC $\beta$-glucan (SCG, $50 \mathrm{mg} / \mathrm{kg} /$ day) was orally gavaged in control mice once a day for 14 days. Second, LPS $(10 \mu \mathrm{g} / \mathrm{kg}$, dissolved in $0.1 \mathrm{~mL}$ of saline) was intraperitoneally injected in mice once a day for 10 days according to the method of Jang et al. [15] and HDB1258 (LL, $1 \times 10^{8} \mathrm{CFU} / \mathrm{mouse} /$ day; LH, $1 \times 10^{9}$ $\mathrm{CFU} / \mathrm{mouse} /$ day) was orally gavaged once a day for 14

(a)

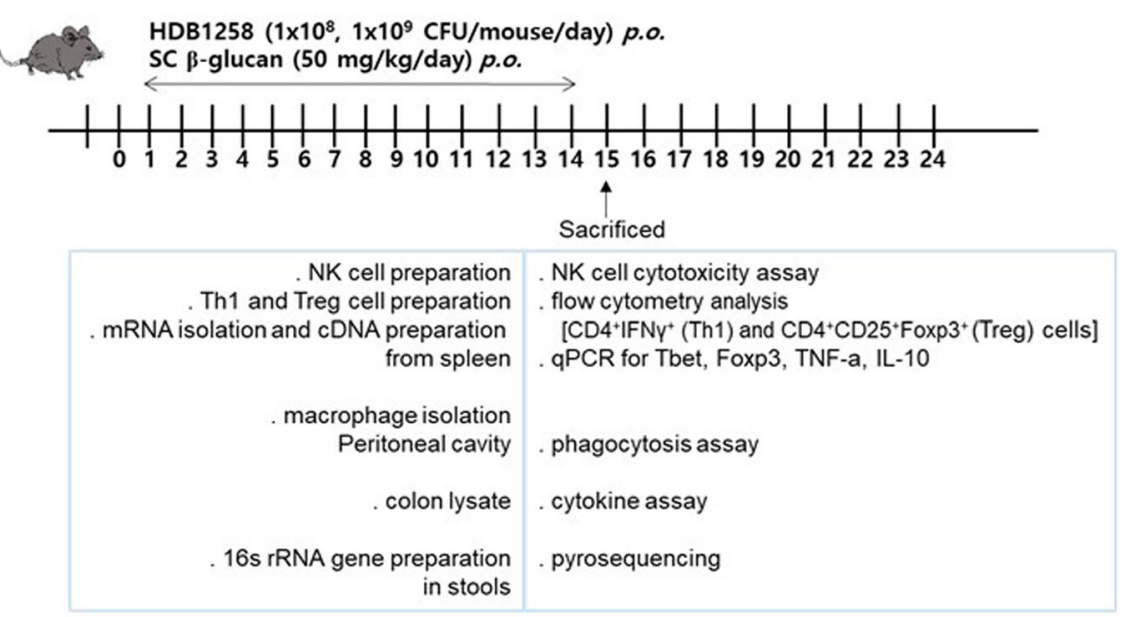

(b)

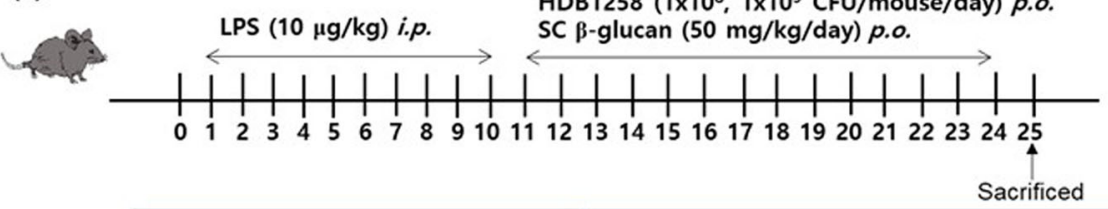

\begin{tabular}{|c|c|}
\hline $\begin{array}{r}\text { NK1 and Treg cell preparation } \\
\text { ThRNA isolation and cDNA preparation } \\
\text { from spleen }\end{array}$ & 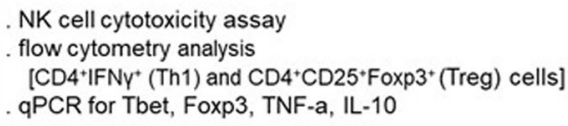 \\
\hline $\begin{array}{r}\text { macrophage isolation } \\
\text { Peritoneal cavity }\end{array}$ & . phagocytosis assay \\
\hline colon lysate & cytokine assay \\
\hline $\begin{array}{r}\text { 16s rRNA gene preparation } \\
\text { in stools }\end{array}$ & pyrosequencing \\
\hline
\end{tabular}

Fig. 8 In vivo experimental schedules. a Experimental schedule in healthy control mice. b Experimental schedule in mice with LPS-induced systemic inflammation 
days from next day after the final treatment with LPS. Mice were sacrificed $20 \mathrm{~h}$ after the final treatment with test agents by $\mathrm{CO}_{2}$ inhalation.

\section{Flow cytometric analysis of Th1 and Treg cells in the spleen}

For the flow cytometric analysis of Th1 and Treg cells in the spleen, spleens were removed from mice, crushed, lysed with Tris-buffered ammonium chloride, suspended in RPMI 1640 medium, and then filtered. The CD4 T cells were isolated from the filtrates using a Pan $\mathrm{T}$ cell Isolation Kit II [37]. Isolated $\mathrm{T}$ cells were fixed and stained with anti-IFN $\gamma$ or anti-Foxp3 antibodies. The stained cells $(1 \times$ $10^{5}$ cells) then analyzed by a flow cytometer (Accuri ${ }^{\mathrm{Tm}}$ C6 Flow Cytometer, BD, Piscataway, NJ).

\section{Preparation of natural killer from splenocytes and its cytotoxicity assays}

For the cytotoxic activity assay of splenic natural killer (NK) cells, NK cells were isolated from splenocytes prepared from the spleen of mice by using a NK cell isolation kit, as described previously [38]. The tumoricidal activity of the NK cells was evaluated by measuring the cytotoxicity against YAC-1 cells labeled with a Vybrant CFDA SE Cell Tracer kit according to the manufacturer's protocol. NK cells $\left(5 \times 10^{5}\right.$ per well $)$ in the 96 well microplates were cultured with YAC-1 cells $\left(5 \times 10^{5}\right.$ per well) for $24 \mathrm{~h}$. The cells were washed and stained with propodium iodide and analyzed by a flow cytometer, as reported previously [38].

\section{Phagocytosis assay of peritoneal macrophages}

Peritoneal macrophages were prepared as described previously [15]. Macrophage cells $\left(1 \times 10^{6}\right.$ cell/well $)$ was incubated with Candida albicans $\left(1 \times 10^{4} \mathrm{CFU} /\right.$ well, purchased from Korean Culture Center of Microorganisms (Seoul, Korea) in the 24-well microplates with complete RPMI 1640 medium and cultured for $24 \mathrm{~h}$. The cultured supernatant $(0.2 \mathrm{~mL})$ was inoculated in Sabouraud dextrose agar for $24 \mathrm{~h}$ at $30^{\circ} \mathrm{C}$. The phagocytic activity (\%) was indicated as [1-(the number of Candida albicans colonies grown in SDA per the number of Candida albicans initially incubated with macrophages) $] \times 100$.

\section{Assay of myeloperoxidase activity}

Myeloperoxidase activity was assayed according to the method of Jang et al. [15]. Colons were homogenized with cold RIPA lysis buffer and centrifuged at 10,000 $\mathrm{g}$ for $10 \mathrm{~min}$. The supernatant was used as a crude enzyme solution. An aliquot $(0.05 \mathrm{~mL})$ of the supernatant was added in the reaction mixture $(0.95 \mathrm{~mL})$ containing $0.03 \%$ hydrogen peroxide and $1.6 \mathrm{mM}$ tetramethylbenzidine. The absorbance at $650 \mathrm{~nm}$ time was monitored over $5 \mathrm{~min}$. Activity was defined as the quantity degrading $1 \mu \mathrm{mol} / \mathrm{mL}$ of peroxide.

Quantitative real time-polymerase chain reaction (qPCR) For the assay of cytokine expression levels in the spleen, the qPCR was performed according to Kim et al. [20]. Briefly, the spleen was removed, homogenized. Total RNA was isolated with RNeasy Mini Kit (Qiagen, Hilden, Germany). The first-strand cDNA was synthesized by PrimeScript II 1st strand cDNA synthesis kit (Takara Bio Inc., Kanagawa, Japan) according to manufacturer's protocol. The qPCR for TNF- $\alpha$, IL-10, T-bet, Foxp3, and $\beta$-actin was performed utilizing Takara thermal cycler, which used SYBR premix agents (Takara Bio Inc.): activation of DNA polymerase at $95^{\circ} \mathrm{C}$ for $5 \mathrm{~min}$ and 45 cycles of amplification at $95^{\circ} \mathrm{C}$ for $10 \mathrm{~s}$ and at $60{ }^{\circ} \mathrm{C}$ for $30 \mathrm{~s}[38,39]$. The normalized expression of the assayed genes (TNF- $\alpha$, IL-10, Foxp3, T-bet, and $\beta$-actin: their primers are described in Table S7), with respect to $\beta$-actin, was computed for all samples by using the Microsoft Excel data spreadsheet.

\section{Elisa}

Colon tissues were lysed with ice-cold lysis RIPA buffer containing $50 \mathrm{mM}$ Tris- $\mathrm{HCl}$ (pH 8.0), $150 \mathrm{mM}$ sodium chloride, 1.0\% Igepal CA-63, 0.5\% sodium deoxycholate, $0.1 \%$ sodium dodecyl sulfate (SDS), $1 \%$ phosphatase inhibitor cocktail and $1 \%$ protease inhibitor cocktail and were centrifuged $\left(10,000 \mathrm{~g}, 4{ }^{\circ} \mathrm{C}\right.$, and $\left.10 \mathrm{~min}\right)$ [17]. For the assay of cytokines, colon homogenate supernatants were transferred in 96-well plate and assayed using ELISA Kits.

\section{Determination of fecal $\lg A$}

The fresh feces $(0.1 \mathrm{~g})$ was collected in the colon of mice after the sacrifice, suspended in phosphate-buffered saline, vortexed at $4{ }^{\circ} \mathrm{C}$ for $20 \mathrm{~min}$, and centrifuged (10 min, $16,000 \mathrm{~g}$, and $4{ }^{\circ} \mathrm{C}$ ). The resulting supernatants were used for the assay of IgA. The IgA level was determined using mouse IgA ELISA kit (Invitrogen, Carlsbad, USA).

\section{Immunofluorescence assay}

Immunofluorescence assay was performed according to the method of Kim et al. [18]. Briefly, the colon was post-fixed with $4 \%$ paraformaldehyde, cytoprotected in $30 \%$ sucrose solution, freezed, and cut using a cryostat (Leica, Nussloch, Germany). The section was washed with phosphate-buffered saline, incubated with antibodies for NF-kB (1:100, Cell Signaling Technology, Beverly, MA: cat \# 8242S) and CD11c (1:200, Abcam, Cambridge, UK: cat \#ab33483) antibody overnight, and treated with the secondary antibody for $2 \mathrm{~h}$. A secondary antibody conjugated with the Alexa Fluor 488 (1:200, Invitrogen) or Alexa Fluor 594 (1:200, Invitrogen) was 
incubated to visualize. Nuclei were stained with DAPI. The stained sections were observed using a confocal microscope (Nanoscope Systems, Inc., Daejeon, Korea).

\section{$16 \mathrm{~S}$ rRNA gene pyrosequencing}

The bacterial genomic DNA was extracted for the fresh feces of mice using a QIAamp DNA stool mini kit according to Kim et al. [18]. The genomic DNA was amplified using barcoded primers targeted the bacterial $16 \mathrm{~S}$ rRNA V4 region gene. Each amplicon was sequenced using Illumina iSeq 100 (San Diego, CA). Functional genes was predicted using the phylogenetic investigation of communities by reconstruction of unobserved states (PICRUSt) $[18,40]$. Linear discriminant analysis (LDA) and cladograms were pictured using the LDA effect size (LefSe) on Galaxy platform (https://huttenhower.sph. harvard.edu/galaxy/) [41].

\section{Statistical analysis}

All data are indicated as the means \pm standard deviation (SD) and conducted GraphPad Prism 8 (GraphPad Software, Inc., San Diego, CA, USA). The significance was analyzed by unpaired Student's $t$-test (for myeloperoxidase activity) and Kruskal-Wallis test with Dunn's post-hoc test for non-parametric analysis (for other experimental data) $(p<0.05)$.

\section{Abbreviations}

IFN: Interferon; IL: Interleukin; LPS: Lipopolysaccharide; NK: Natural killer; OUT: Operational taxonomic unit; PCoA: Principal coordinate analysis; SC: Saccharomyces cerevisiae; Th: Helper T; TNF: Tumor necrosis factor; Treg: Regulatory $\mathrm{T}$

\section{Supplementary Information}

The online version contains supplementary material available at https://doi. org/10.1186/s12866-021-02192-4.

Additional file 1: Table S1. Primer sequences used in the present study. Table S1. Effect of HDB1258 on the gut microbiota composition at the family level in mice. Table S2. Effect of HDB1258 on the gut microbiota composition at the genus level in mice. Table S3. Effect of HDB1258 on the gut microbiota composition at the species level in mice. Table S4. Effect of HDB1258 on the gut microbiota composition at the family level in mice with LPS-induced systemic inflammation. Table S5. Effect of HDB1258 on the gut microbiota composition at the genus level in mice with LPS-induced systemic inflammation. Table S6. Effect of HDB1258 on the gut microbiota composition at the species level in mice with LPS-induced systemic inflammation. Table S7. Primer sequences used in the present study. Figure S1. Effect of probiotics isolated from the feces of breastfeeding infants on the TNF-a expression in macrophages. Figure S2. The correlation between gut microbiota (at the species level) and ratio of TNF-a to IL-10 expression in the healthy mice. Figure S3. The correlation between gut microbiota (at the species level) and ratio of TNF-a to IL-10 expression in mice with LPS-induced systemic inflammation

\section{Acknowledgements}

This research was funded by the Medical Research Program through the National Research Foundation of Korea (NRF) funded by the Ministry of Science and ICT (NRF- 2017R1A5A2014768).

\section{Authors' contributions}

SKH, SL, and DHK: conceptualization and experiment design; SKH, YJS, DYL, KMK, SJY, and DSK; experiment and data analysis; SKH, YJS, DYL, KMK, SJY, DSK, and JWC: investigation; SKH, YJS, SL, and DHK: manuscript writing. All authors reviewed and agreed to the published version of the manuscript.

\section{Funding}

This research was funded by the Medical Research Program through the National Research Foundation of Korea (NRF) funded by the Ministry of Science and ICT (NRF- 2017R1A5A2014768).

Availability of data and materials

Pyrosequencing reads were deposited in the short read archive of NCBI under accession number PRJNA678595.

\section{Declarations}

Ethics approval and consent to participate

All animal experimental procedures were approved by the Institutional Animal Care and Use Committee of the University (IACUC No. KUSASP20018).

Consent for publication

Not applicable.

\section{Competing interests}

The authors have declared no conflict of interest.

\section{Author details}

${ }^{1}$ Neurobiota Research Center, College of Pharmacy, Kyung Hee University, 26 , Kyungheedae-ro, Dongdaemun-gu, Seoul 02447, South Korea. ${ }^{2} \mathrm{HYUNDAI}$ BIOLAND Co., Ltd., Ansan 15407, South Korea.

Received: 20 November 2020 Accepted: 7 April 2021

Published online: 13 May 2021

\section{References}

1. Wu HJ, Wu E. The role of gut microbiota in immune homeostasis and autoimmunity. Gut Microbes. 2012;3(1):4-14. https://doi.org/10.4161/ gmic.19320.

2. Belkaid $Y$, Hand T. Role of the microbiota in immunity and inflammation. Cell. 2014;157(1):121-41. https://doi.org/10.1016/j.cell.2014.03.011.

3. Pickard JM, Zeng MY, Caruso R, Núñez G. Gut microbiota: role in pathogen colonization, immune responses and inflammatory disease. Immunol Rev. 2017;279(1):70-89. https://doi.org/10.1111/imr.12567.

4. Kany S, Vollrath JT, Relja B. Cytokines in inflammatory disease. Int J Mol Sci. 2019;20(23):6008. https://doi.org/10.3390/ijms20236008.

5. Mendes V, Galvão I, Vieira AT. Mechanisms by which the gut microbiota influences cytokine production and modulates host inflammatory responses. J Interf Cytokine Res. 2019;39(7):393-409. https://doi.org/10.1089/ jir.2019.0011.

6. Chaplin DD. Overview of the immune response. J Allergy Clin Immunol. 2010;125(Suppl 2):S3-23. https://doi.org/10.1016/j.jaci.2009.12.980.

7. Kaiko GE, Horvat JC, Beagley KW, Hansbro PM. Immunological decisionmaking: how does the immune system decide to mount a helper T-cell response? Immunology. 2008;123(3):326-38. https://doi.org/10.1111/j.1365-2 567.2007.02719.x.

8. Gaudino SJ, Kumar P. Cross-talk between antigen presenting cells and T cells impacts intestinal homeostasis, bacterial infections, and tumorigenesis. Front Immunol. 2019;10:360. https://doi.org/10.3389/fimmu.2019.00360.

9. Haapakoski R, Ebmeier KP, Alenius H, Kivimäkia M. Innate and adaptive immunity in the development of depression: an update on current knowledge and technological advances. Prog Neuro-Psychopharmacol Biol Psychiatry. 2016;66:63-72. https://doi.org/10.1016/j.pnpbp.2015.11.012.

10. Zheng D, Liwinski T, Elinav E. Interaction between microbiota and immunity in health and disease. Cell Res. 2020;30(6):492-506. https://doi.org/10.1038/ s41422-020-0332-7.

11. Hemarajata P, Versalovic J. Effects of probiotics on gut microbiota: mechanisms of intestinal immunomodulation and neuromodulation. Ther Adv Gastroenterol. 2013;6(1):39-51. https://doi.org/10.1177/1756283 X12459294. 
12. Saulnier DM, Ringel $Y$, Heyman MB, Foster JA, Bercik P, Shulman RJ, et al. The intestinal microbiome, probiotics and prebiotics in neurogastroenterology. Gut Microbes. 2013;4(1):17-27. https://doi.org/10.41 61/gmic.22973.

13. Kok CR, Hutkins R. Yogurt and other fermented foods as sources of healthpromoting bacteria. Nutr Rev. 2018;76(Supp 1):4-15. https://doi.org/10.1093/ nutrit/nuy056.

14. Jang HM, Lee HJ, Jang SE, Han MJ, Kim DH. Evidence for interplay among antibacterial-induced gut microbiota disturbance, neuro-inflammation, and anxiety in mice. Mucosal Immunol. 2018;11(5):1386-97. https://doi.org/10.1 038/s41385-018-0042-3.

15. Jang HM, Lee KE, Lee HJ, Kim DH. Stress immobilization stress-induced Escherichia coli causes anxiety by inducing NF-kB activation through gut microbiota disturbance. Sci Rep. 2018;8(1):13897. https://doi.org/10.1038/s41 598-018-31764-0.

16. Jang SE, Lim SM, Jeong JJ, Jang HM, Lee HJ, Han MJ, et al. Gastrointestinal inflammation by gut microbiota disturbance induces memory impairment in mice. Mucosal Immunol. 2018;11(2):369-79. https://doi.org/10.1038/mi.2017.49.

17. Jang HM, Lee KE, Kim DH. The preventive and curative effects of Lactobacillus reuteri NK33 and Bifidobacterium adolescentis NK98 on immobilization stress-induced anxiety/depression and colitis in mice. Nutrients. 2019;11(4):819. https://doi.org/10.3390/nu11040819.

18. Kim JK, Lee KE, Lee SA, Jang HM, Kim DH. Interplay between human gut bacteria Escherichia coli and Lactobacillus mucosae in the occurrence of neuropsychiatric disorders in mice. Front Immunol. 2020;11:273.

19. Kim HI, Yun SW, Han MJ, Jang SE, Kim DH. IL-10 expression-inducing gut bacteria alleviate high-fat diet-induced obesity and hyperlipidemia in mice. J Microbiol Biotechnol. 2020;30(4):599-603. https://doi.org/10.4014/jmb.1 912.12014

20. Jung IS, Jeon MG, Oh DS, Jung YJ, Kim HS, Bae D, et al. Micronized, heattreated Lactobacillus plantarum LM1004 alleviates cyclophosphamideinduced immune suppression. J Med Food. 2019;22(9):896-906. https://doi. org/10.1089/jmf.2018.4378

21. Pelizon AC, Kaneno R, Soares AMVC, Meira DA, Sartori A. Immunomodulatory activities associated with beta-glucan derived from Saccharomyces cerevisiae. Physiol Res. 2005;54(5):557-64.

22. Shmarina GV, Pukhalsky AL, Kokarovtseva SN, Pukhalskaya DA, Shabalova LA, Kapranov NI, et al. Tumor necrosis factor-alpha/interleukin-10 balance in normal and cystic fibrosis children. Mediat Inflamm. 2001;10(4):191-7. https://doi.org/10.1080/09629350123387.

23. Gomes RG, Brito CAA, Martinelli VF, Santos RND, Gomes FODS, Peixoto CA et al. HLA-G is expressed in intestinal samples of ulcerative colitis and Crohn's disease patients and HLA-G5 expression is differentially correlated with TNF and IL-10 cytokine expression. Hum Immunol. 2018;79(6):477-84. https://doi.org/10.1016/j.humimm.2018.03.006

24. Iwasaki A, Medzhitov R. Control of adaptive immunity by the innate immune system. Nat Immunol. 2015;16(4):343-53. https://doi.org/10.1038/ ni.3123.

25. Turner MD, Nedjai B, Hurst T, Pennington DJ. Cytokines and chemokines: at the crossroads of cell signalling and inflammatory disease. Biochim Biophys Acta 2014. 1843:2563-82.

26. Furiati SC, Catarino JS, Silva MV, Silva RF, Estevam RB, Teodoro RB, et al. Th1, Th17, and Treg responses are differently modulated by TNF-a inhibitors and methotrexate in psoriasis patients. Sci Rep. 2019;9(1):7526. https://doi.org/1 0.1038/s41598-019-43899-9.

27. Lazar V, Ditu LM, Pircalabioru GG, Gheorghe I, Curutiu C, Holban AM, et al. Aspects of gut microbiota and immune system interactions in infectious diseases, immunopathology, and cancer. Front Immunol. 2018;9:1830. https://doi.org/10.3389/fimmu.2018.01830.

28. Mantis NJ, Rol N, Corthésy B. Secretory IgA's complex roles in immunity and mucosal homeostasis in the gut. Mucosal Immunol. 2011;4(6):603-11. https://doi.org/10.1038/mi.2011.41.

29. Strugnell RA, Wijburg OLC. The role of secretory antibodies in infection immunity. Nat Rev Microbiol. 2010;8(9):656-67. https://doi.org/10.1038/ nrmicro2384.

30. Villena J, Chiba E, Tomosada Y, Salva S, Marranzino G, Kitazawa H, et al. Orally administered Lactobacillus rhamnosus modulates the respiratory immune response triggered by the viral pathogen-associated molecular pattern poly(l:C). BMC Immunol. 2012;13(1):53. https://doi.org/10.1186/14 71-2172-13-53.
31. Nigar S, Yamamoto Y, Okajima T, Shigemori S, Sato T, Ogita T, et al. Synergistic oligodeoxynucleotide strongly promotes CpG-induced interleukin-6 production. BMC Immunol. 2017;18(1):44. https://doi.org/10.11 86/s12865-017-0227-7.

32. Zhang J, Ma JY, Li QH, Su H, Sun X. Lactobacillus rhamnosus GG induced protective effect on allergic airway inflammation is associated with gut microbiota. Cell Immunol. 2018;332:77-84. https://doi.org/10.1016/j. cellimm.2018.08.002

33. Wang H, Gao K, Wen K, Allen IC, Li G, Zhang W, et al. Lactobacillus rhamnosus GG modulates innate signaling pathway and cytokine responses to rotavirus vaccine in intestinal mononuclear cells of gnotobiotic pigs transplanted with human gut microbiota. BMC Microbiol. 2016;16(1):109. https://doi.org/10.1186/s12866-016-0727-2.

34. Yoo JY, Groer M, Dutra SVO, Sarkar A, McSkimming DI. Gut microbiota and immune system interactions. Microorganisms. 2020:8(10):1587. https://doi. org/10.3390/microorganisms8101587.

35. Zeng MY, Inohara N, Nuñez G. Mechanisms of inflammation-driven bacterial dysbiosis in the gut. Mucosal Immunol. 2017;10(1):18-26. https://doi.org/1 0.1038/mi.2016.75.

36. Kim KM, Yang SJ, Kim DS, Lee CW, Kim HY, Lee S, et al. Probiotic properties and immune-stimulating effect of the Jeju lava seawater mineral-coated probiotics. LWT - Food Sci Technol. 2020;126:109299. https://doi.org/10.101 6/j.lwt.2020.109299.

37. Lim SM, Jeong JJ, Choi HS, Chang HB, Kim DH. Mangiferin corrects the imbalance of Th17/Treg cells in mice with TNBS-induced colitis. Int Immunopharmacol. 2016;34:220-8. https:/doi.org/10.1016/j.intimp.2016.03.004

38. Jang $\mathrm{SE}$, Joh EH, Lee HY, Ahn YT, Lee JH, Huh CH, et al. Lactobacillus plantarum HY7712 ameliorates cyclophosphamide-induced immunosuppression in mice. J Microbiol Biotechnol. 2013;23(3):414-21. https://doi.org/10.4014/jmb.1210.10010.

39. Lim SM, Lee SY, Jeong JJ, Choi HS, Chang HB, Kim DH. DW2007 ameliorates colitis and rheumatoid arthritis in mice by correcting Th17/Treg imbalance and inhibiting NF-kB activation. Biomol Ther (Seoul). 2016;24(6):638-49. https://doi.org/10.4062/biomolther.2016.018

40. Langille MG, Zaneveld J, Caporaso JG, McDonald D, Knights D, Reyes JA et al. Predictive functional profiling of microbial communities using $16 \mathrm{~S}$ rRNA marker gene sequences. Nat Biotechnol. 2013;31(9):814-21. https://doi. org/10.1038/nbt.2676.

41. Segata N, Izard J, Waldron L, Gevers D, Miropolsky L, Garrett WS, et al. Metagenomic biomarker discovery and explanation. Genome Biol. 2011; 12(6):R60. https://doi.org/10.1186/gb-2011-12-6-r60.

\section{Publisher's Note}

Springer Nature remains neutral with regard to jurisdictional claims in published maps and institutional affiliations.

Ready to submit your research? Choose BMC and benefit from:

- fast, convenient online submission

- thorough peer review by experienced researchers in your field

- rapid publication on acceptance

- support for research data, including large and complex data types

- gold Open Access which fosters wider collaboration and increased citations

- maximum visibility for your research: over $100 \mathrm{M}$ website views per year

At $\mathrm{BMC}$, research is always in progress.

Learn more biomedcentral.com/submissions 